\title{
Interleukin-8 levels and activity in delayed-healing human thermal wounds
}

\author{
JOSEPH A. IOCONO, MDa; KEVIN R. COLLERAN, BSa; DANIEL G. REMICK MD'; BRENDA W. GILLESPIE, PhD; \\ H. PAUL EHRLICH, PhDa; WARREN L. GARNER, MD ${ }^{d}$
}

There are numerous causes for slow or delayed wound healing. Because slowly healing wounds are often inflamed, we quantitated the inflammatory chemokine, interleukin-8, produced by slowly healing human burn wounds and compared this to interleukin-8 from healed wounds and normal intact skin. Interleukin-8 levels were increased significantly in unhealed wounds $(19.7 \mathrm{ng} / \mathrm{ml})$ compared to healed wounds $(7.7 \mathrm{ng} / \mathrm{ml})$ or normal skin $(5.7 \mathrm{ng} / \mathrm{ml})$. Interleukin8 in these ranges was added to adult human keratinocytes and fibroblasts. Interleukin- 8 significantly decreased keratinocyte replication but had no effect on fibroblast replication. The rate or final degree of fibroblast populated collagen lattice contraction was inhibited at interleukin-8 concentrations between 10 and 30 ng/ml, but not altered at concentrations below $10 \mathrm{ng} / \mathrm{ml}$ and above $100 \mathrm{ng} / \mathrm{ml}$. The concurrent application of indomethacin at $10 \mu \mathrm{g} / \mathrm{ml}$ reversed this interleukin-8 induced inhibition. Interleukin-8 inhibited myosin ATPase activity, apparently by reducing the phosphorylation of nonmuscle myosin light chain. We conclude that elevated levels of interleukin- 8 may be found during delayed healing, and these elevated interleukin-8 levels may directly contribute to retarded wound closure. (WOUND REP REG 2000;8:216-225)

Wound healing is usually an orchestrated series of steps beginning with inflammation, proceeding through matrix synthesis and cell replication and followed by tissue remodeling and scar stabilization. The numerous cellular and humoral interactions during these phases of wound healing are complex and not completely understood. Evolving evidence shows a changing cascade of cell types and functions related to released cytokines and growth factors. For example, macrophages migrate into the

From the Division of Pediatric Surgery, Center, The Pennsylvania State University College of Medicine, Hershey, Pennsylvania; and Department of Pathology, , University of Michigan Medical School, Center for Statistical Consultation and Research,c University of Michigan, and Section of Plastic and Reconstructive Surgery, University of Michigan Medical School, Ann Arbor, Michigan.

Reprint requests: Warren L. Garner, MD, LAC and USC Burn Center, 1200 N. State Street, Room 12-650, Los Angeles, CA 90033. Fax: (323) 226-2290; Email: wgarner@surgery.usc.edu.

Copyright (c) 2000 by The Wound Healing Society.

ISSN: $1067-1927 \$ 15.00+0$

$\begin{array}{ll}\text { BSA } & \text { Bovine serum albumin } \\ \text { DMEM } & \text { Dulbecco's modified Eagle medium } \\ \text { ELISA } & \text { Enzyme-linked immunosorbent assay } \\ \text { FBS } & \text { Fetal bovine serum } \\ \text { FPCL } & \text { Fibroblast populated collagen lattice } \\ \text { IL-8 } & \text { Interleukin-8 } \\ \text { MLC } & \text { Myosin light chain } \\ \text { MLCK } & \text { MLC kinase } \\ \text { PBS } & \text { Phosphate buffered saline solution } \\ \text { PGE } & \text { Prostaglandin } E_{2} \\ \text { SDS } & \text { Sodium dodecyl sulfate }\end{array}$

wounds in response to acute inflammatory mediators. After an initial participation as inflammatory cells, macrophages release cytokines that stimulate fibroblast migration, replication and new matrix synthesis. The importance of the individual components and order of cells and mediators in achieving normal wound healing is poorly understood. For example, there is limited and conflicting information on the direct effect of inflammatory cytokines on wound healing. ${ }^{1,2}$ Many clinicians believe that inflamed wounds exhibit impaired wound 
closure. Yet, in the absence of inflammation, wound closure is retarded. ${ }^{3}$ Thus, the relationship between the inflammatory phase of wound healing and the eventual success of wound closure is not clear.

Interleukin-8 (IL-8) is a chemokine associated with acute inflammation that is elevated in human wounds. ${ }^{4,5}$ IL-8 is reported to modulate the functions of numerous inflammatory cells involved in the repair process ${ }^{6}$ and is the most studied member of the $\alpha$-subfamily of chemokines. This subfamily of chemokines is characterized by a conserved tri-peptide near the N-terminus, containing cysteines (C-X-C). IL-8 was discovered in $1987,{ }^{7}$ and its 3 -dimensional structure, ${ }^{8}$ gene location, ${ }^{9,10}$ receptor structure and properties, ${ }^{11}$ as well as a variety of functions have been elucidated. ${ }^{12} \mathrm{IL}-8$ is an $8-10 \mathrm{kDa}$ protein found in the form of 2 active isomers; a 77 amino acid form and the more active 72 amino acid isoform. ${ }^{4}$ The 72 amino acid form is used in the experiments presented here. Many cells, including monocytes/macrophages, neutrophils, eosinophils, T-cells, keratinocytes, fibroblasts, astrocytes, endothelial cells and chondrocytes, secrete IL-8 either constitutively or in response to a variety of pro-inflammatory stimuli., ${ }^{43}$ IL-8 binds to specific transmembrane receptors and produces cellular responses through G-protein; phospho-inositol and protein kinase $\mathrm{C}$ mediated signaling mechanisms. ${ }^{14}$ This type of signaling is associated with changes in the organization of fibroblast cytoskeletal stress fibers and focal adhesions. ${ }^{15,16}$ IL-8 is a potent chemoattractant for keratinocytes, neutrophils as well as other leukocytes. ${ }^{17}$ Tumor necrosis factor- $\alpha$, IL- $1 \alpha$, and IL-1 $\beta$ stimulate IL- 8 production in macrophages. ${ }^{12}$ IL-8 appears to have a pathophysiological role in some human diseases ${ }^{17}$ and elevated levels of IL-8 have been associated with increased inflammation in skin diseases such as psoriasis. ${ }^{6}$ Finally, increased levels of IL- 8 have been reported within healing burn wounds. ${ }^{5}$

Fibroblasts both synthesize and organize collagen fibrils, processes essential for wound healing. An in vitro model for the study of fibroblasts and collagen interactions is the fibroblast populated collagen lattice (FPCL) model, first introduced by Bell and coworkers in 1979.18 A FPCL is cast by mixing together fibroblasts, culture medium containing serum and soluble collagen. When the temperature is raised to $37^{\circ} \mathrm{C}$ the collagen polymerizes trapping the cells within the rapidly forming gel. Over time, the FPCL undergoes a reduction in size called lattice contraction, which can be used to quantify the interactions of fibroblasts and collagen. The forces responsible for lattice contraction are generated by fibroblasts as they pack collagen fibrils into denser bundles. ${ }^{19}$
Fibroblasts require mRNA and protein synthesis, as well as the participation of microtubules, microfilaments, $\alpha_{2} \beta_{1}$ integrin surface receptors, and myosin-ATPase for optimizing lattice contraction. ${ }^{18,20}$ A number of agents are reported to inhibit lattice contraction including $\mathrm{IL}-1 \alpha$, prostaglandin $\mathrm{E}_{2}\left(\mathrm{PGE}_{2}\right)$ and cholera toxin. IL- $1 \alpha$ induces the synthesis of $\mathrm{PGE}_{2}$ that promotes cAMP formation, which in turn prevents the activation of myosin ATPase by blocking the phosphorylation of its regulatory peptide, the myosin light chain..$^{20}$ Indomethacin, a cyclooxygenase inhibitor, blocks the production of $\mathrm{PGE}_{2}$ and restores lattice contraction to control levels in the presence of IL-1 $\alpha$.

Although IL-8 is known to be present in wounds, its actions within these wounds are not fully understood. In this study we measured the concentration of IL-8 in human healing wounds. Using in vitro wound healing models, the effects of these measured IL-8 concentrations on activities of wound healing were examined. It is proposed that IL-8 has direct effects upon fibroblasts and keratinocytes that are independent of the effects mediated by inflammatory cells. These results suggest a mechanism whereby excessive inflammation may have an inhibitory effect on normal wound healing.

\section{MATERIALS AND METHODS}

Tissue biopsies were obtained from patients who had sustained burn injuries more than 3 weeks previously. All patients provided informed consent prior to participating in this study, and the protocol had been approved by the University of Michigan Institutional Review Board. All patients underwent burn wound treatment using standard protocols including daily antimicrobial dressings for partial-thickness injuries, skin grafting for full-thickness injuries, and twice-weekly biopsy for quantitative bacterial counts. In some patients these treatments were not completely effective and small areas of nonhealing or slow-healing wounds remained. Six of these wounds were partial thickness injuries that did not heal within three weeks as expected. These wounds were $2-4 \mathrm{~cm}$ in diameter, a size that would normally be expected to heal by contraction or re-epithelialization within 2-4 weeks. The remaining wounds were small full-thickness wounds, $1-3 \mathrm{~cm}$ in diameter. They had lost graft from infection or shear, been treated to clear infection, but then did not heal as expected. All wounds that were infected as quantitated by bacterial counts greater than $10^{5}$ bacteria per gram of tissue were not included in this study. Full-thickness punch biopsies, $6 \mathrm{~mm}$ in diameter were obtained from healed and unhealed portions of the 
burn wounds and normal, uninjured skin from the same individual. Each biopsy was incubated for 18 hours in 3 $\mathrm{ml}$ of MCDB 110 medium (Sigma Chemical Co., St. Louis, MO), supplemented with $0.2 \%$ bovine serum albumin (BSA) and $2.5 \mu \mathrm{g} / \mathrm{ml}$ gentamicin (Sigma Chemical Co.) at $37{ }^{\circ} \mathrm{C}, 95 \%$ air and $5 \% \mathrm{CO}_{2}$. The resulting conditioned media were frozen for IL-8 levels.

\section{Interleukin-8 assay}

The enzyme-linked immunosorbent assay (ELISA) for IL-8 was essentially that reported by DeForge and Remick. ${ }^{21}$ Briefly, a rabbit IgG polyclonal antibody to recombinant mononuclear cell-derived (72 amino acid form) human IL-8 was isolated with a protein A-agarose column (Pierce, Inc., Rockford IL). ELISA plates (Nunc-Immuno Plate Maxisorb, Inc., Neptune, NJ) were coated with 50 $\mu \mathrm{l} /$ well of anti-IL-8 monoclonal antibody (R \& D Systems, Minneapolis, MN) diluted to $1 \mu \mathrm{g} / \mathrm{ml}$ and incubated overnight at $4{ }^{\circ} \mathrm{C}$. The plates were washed with PBS containing $0.05 \% \mathrm{v} / \mathrm{v}$ polysorbinate 20 (Tween-20) to block the reaction. PBS containing $2 \%$ BSA was added for 1-2 hours at room temperature. The plates were washed, biotinylated rabbit antihuman IL-8 antibody was added for 30 minutes, then avidin-horse-radish peroxidase (Dako, Inc., Carpinteria, CA) at $1: 5000$ was added. After 30 minutes the plates were washed and substrate solution $(0.67 \mathrm{mg} / \mathrm{ml}$ orthophenylenediamine dichloride, $0.0125 \%$ $\mathrm{H}_{2} \mathrm{O}_{2}$ in $0.25 \mathrm{mM}$ citrate phosphate buffer, $\mathrm{pH} 5.0$ ) was added. Color development was stopped by adding $50 \mu \mathrm{l}$ $3 \mathrm{M} \mathrm{H}_{2} \mathrm{SO}_{4}$ after 4-5 minutes. The absorbance at $490 \mathrm{~nm}$ on an ELISA reader was used to determine the concentrations of IL-8 based upon a standard curve prepared with human recombinant IL-8 (R \& D Systems). The lower limit of sensitivity for the assay was $45 \mathrm{pg} / \mathrm{ml}$.

\section{Cell culture}

All cell strains were derived from discarded human skin. Two human dermal fibroblast lines were derived from newborn foreskin explant outgrowths. Fibroblasts were maintained in monolayer with Dulbecco's modified Eagle medium (DMEM) containing 10\% fetal bovine serum (FBS, Gibco-Life Science Technologies, Gaithersburg, MD), $2 \mathrm{mM}$ L-glutamine and $20 \mu \mathrm{g} / \mathrm{ml}$ gentamicin ("complete DMEM"). Cells were used between their fifth and sixteenth passage. Six human keratinocyte and two additional fibroblast strains were derived from skin discarded from adult women undergoing breast reduction. The skin was treated in $0.15 \%$ trypsin, overnight, and the epidermis removed by mechanical scraping with a scalpel blade. Particulate matter was removed by filtration through nylon mesh and the cell suspension plated in complete medium (KGM, Clonetics Corp., San Diego, CA) con- taining $2 \%$ calcium free FBS, and antibiotics. ${ }^{22}$ Complete medium was supplemented with $0.6 \times 10^{-6} \mathrm{M}$ hydrocortisone, $5 \mathrm{ng} / \mathrm{ml}$ epidermal growth factor, $5 \mathrm{mg} / \mathrm{ml}$ insulin and $6 \mathrm{mg}$ percentage bovine pituitary extract (Clonetics Corp., San Diego, CA). Keratinocytes were used at passage two or three.

\section{Cell replication}

Triplicate samples of keratinocytes or fibroblasts were plated into 12-well plates at a density of 50,000 cells per well. The following day fresh media with or without the addition of varying concentrations of IL-8 was added. New media and chemokine were added at two-day intervals. The cells were harvested on the designated days by trypsinization and cell number determined by using a Coulter Counter.

\section{Collagen preparation}

Native collagen was acetic acid extracted from rat-tail tendon as previously described. ${ }^{23}$ Briefly, $0.5 \mathrm{M}$ acetic acid solubilized collagen was centrifuged, precipitated by adding $\mathrm{NaCl}(10 \% \mathrm{w} / \mathrm{v})$, centrifuged and the collagen pellet re-suspended in $0.1 \mathrm{M}$ acetic acid. The collagen solution was exhaustively dialyzed against $1 \mathrm{mM} \mathrm{HCl}$ at $4{ }^{\circ} \mathrm{C}$, frozen, lyophilized, re-suspended in $1 \mathrm{mM} \mathrm{HCl}$ (sterile) at $5 \mathrm{mg} / \mathrm{ml}$ and then stored at $4{ }^{\circ} \mathrm{C}$. Based upon sodium dodecyl sulfate-polyacrylamide gel electrophoresis (SDS-PAGE) analysis, only collagen protein was detectable by Coomassie Brilliant Blue staining.

\section{FPCL contraction}

FPCL in a total volume of $2 \mathrm{ml}$ were cast by mixing together freshly trypsinized fibroblasts $(100,000)$ with complete DMEM and $2.5 \mathrm{mg}$ collagen. Aliquots of $0.5 \mathrm{ml}$ of the mixture were added to wells of a 24-well tissue culture dish. The dish was placed in a $37^{\circ} \mathrm{C}$ incubator with $95 \%$ air and $5 \% \mathrm{CO}_{2}$. Under these conditions, the collagen/fibroblast mixture polymerized in less than 90 seconds. Any additions were made in $10 \mu \mathrm{l}$ aliquots and were added to the cell suspension prior to the addition of collagen. The treatment groups were: Control, PBS; IL-8 alone at 1, 3, 10, 30, 100 or $300 \mathrm{ng} / \mathrm{ml}$; and a combination of IL-8 (30 ng/ml) and indomethacin $(10 \mu \mathrm{g} / \mathrm{ml}$, Sigma Chemical Co.).

\section{Myosin ATPase activity assay}

Four sets of sterile $22 \times 22 \mathrm{~mm}$ glass cover slips in 35 $\mathrm{mm}$ Petri dishes containing $2 \mathrm{ml}$ of complete DMEM with plated fibroblasts $(\sim 5000)$ received $10 \mu \mathrm{l}$ of either PBS (control) or $60 \mathrm{ng}$ (final concentration $30 \mathrm{ng} / \mathrm{ml}$ ) of IL-8. At 24 hours, the medium was removed, the coverslips rinsed with PBS, the cells permeabilized by serial glycerol treatments of 50,25, 12.5 and $5 \%$ glycerol $(\mathrm{v} / \mathrm{v}){ }^{24}$ 
Half of the coverslips were rinsed in PBS and immediately fixed in $4 \%$ paraformaldehyde for 5 minutes, rinsed and retained in PBS. The remaining coverslips had the $5 \%$ glycerol buffer replaced with $1 \mathrm{mM}$ ATP in $5 \mathrm{mM}$ $\mathrm{MgCl}_{2}, 30 \mathrm{mM} \mathrm{KCl}, 0.1 \mathrm{mM} \mathrm{CaCl}{ }_{2}$ and $10 \mathrm{mM}$ Tris- $\mathrm{HCl}$ $\mathrm{pH}$ 7.0. After 10 minutes, the coverslips were washed in PBS, fixed and rinsed as described above. Coverslips were viewed using an inverted microscope with phase contrast optics and cell lengths measured by an eyepiecemounted micrometer. Measurements of at least 25 cells from each coverslip were recorded from 3 coverslips from each treatment group (two at time 0 , two with ATP added for 10 minutes). The entire experiment was repeated twice.

\section{Myosin light chain phosphorylation}

Confluent $10 \mathrm{~cm}$ dishes of fibroblasts were incubated with complete DMEM supplemented with either: PBS (control), IL-8 (30 ng/ml) or a combination of IL-8 (30 $\mathrm{ng} / \mathrm{ml})$ and indomethacin $(10 \mu \mathrm{g} / \mathrm{ml})$. After 24 hours, the medium was removed and the cells washed 3 times with PBS. Cells were harvested by scraping and suspended in $1 \mathrm{ml}$ of analysis buffer $(20 \mathrm{mM}$ Tris $\mathrm{HCl}, \mathrm{pH} 7.5$ containing $4 \mathrm{mM}$ EDTA, $137 \mathrm{mM} \mathrm{NaCl}, 10 \%$ glycerol, $1 \%$ Nonidet P-40, $0.15 \mathrm{U} / \mathrm{ml}$ aprotinin, $1 \mathrm{mM}$ phenylmethylsulfonyl fluoride, $10 \mu \mathrm{g} / \mathrm{ml}$ leupeptin, $100 \mathrm{mM}$ sodium fluoride, $2 \mathrm{mM}$ vanadate, and $10 \mathrm{mM}$ sodium pyrophosphate; all from Sigma Chemical Co.). The cell lysates were sonicated, boiled for 10 minutes, centrifuged, and insoluble material discarded. The soluble protein concentration were determined by the Bradford assay (BioRad Laboratories, Inc., Richmond, CA) and samples stored at $-70^{\circ} \mathrm{C}$. For SDS-PAGE, $20 \mu \mathrm{g}$ of protein from each sample was mixed with an equal volume of Laemmli buffer and electrophoresis done on a 4-20\% SDS gradient gel (BioRad Laboratories, Inc.). Proteins were transferred to Immobilon ${ }^{\circledR}$ membrane and probed with monoclonal antibodies to myosin light chain kinase (MLCK), myosin light chain (MLC) or $\beta$-actin (all from Sigma Chemical Co.). Peroxidase reaction using the ECL chemiluminescence kit assay (Amersham Life Technologies, Inc., Arlington Heights, IL) was employed following manufacturer's instructions and the band densities on X-ray film quantitated by densitometry.

\section{Cellular morphology}

Fibroblasts residing in collagen lattices were examined by phase contrast and fluorescence microscopy for gross appearance and orientation of cytoplasmic microfilaments. FPCLs at 24 hours were fixed for 5 minutes in $4 \%$ paraformaldehyde, permeabilized with $0.1 \%$ Triton $\mathrm{X}-100$ in PBS, then incubated with Rh-Phalloidin (Molec- ular Probes, Inc., Eugene, OR) and mounted in PBS: glycerol 9:1 under a coverslip. Fibroblasts within the lattices were viewed and photographed with an Olympus INT-2 microscope equipped with phase contrast and fluorescent optics.

\section{Statistical analysis}

The data on cytokine levels from tissue biopsies were analyzed using ANOVA for a randomized block design. The values were log transformed prior to comparison to compensate for data asymmetry. Pair-wise comparisons between healed, unhealed and normal tissue samples were made using the Tukey-Kramer adjustment for multiple comparisons.

Comparison of FPCL contraction among treatment groups was made using one-way analysis of variance (ANOVA), with Dunnet's test to compare each treatment group against the control group. Differences between treatment groups in cell-contraction studies and densitometry reading of immunoblots were tested using the Student's $t$-test.

The effect of IL-8 concentration on cell replication was investigated using analysis of covariance (ANCOVA). The log of IL-8 concentration (plus 0.1, to avoid taking the log of zero) was used. A linear relationship between cell number and log IL-8 concentration was first assumed. The six cell strains, the three plating times, and the interaction between strains and plates were also entered into the analysis to adjust for known components of human and laboratory variability. Because of an increase in cell numbers between concentrations 0 and 1 , followed by a gradual decrease in cell numbers at the higher concentrations, the linear model was not ideal. This pattern is displayed on a plot of cell number by log IL-8 concentration, with a line that smoothly connects the values at each concentration. The line was calculated using the loess algorithm..$^{25}$ To adjust for this increasing, then decreasing pattern in the ANCOVA, we added an indicator variable for concentration $=0$. This indicator variable was used to test the difference of this point from the line defined by the other IL-8 concentration values.

\section{RESULTS}

The goal of this study was to ascertain whether the IL-8 concentrations produced by biopsies of slow or poorly healing burn wounds would affect in vitro cell functions believed to be important for wound healing. Tissue biopsies were performed on 13 patients with slow healing burn wounds for at least 3 weeks duration. In 12/13 cases matched biopsies of normal skin were obtained and 
Table 1. Interleukin-8 levels released from tissue biopsies

\begin{tabular}{|c|c|c|c|c|c|}
\hline \multirow[b]{2}{*}{ Tissue source } & \multirow[b]{2}{*}{$n$} & \multicolumn{3}{|c|}{ IL-8 concentrations (ng/ml) } & \multirow[b]{2}{*}{$p$ vs. normal } \\
\hline & & Mean \pm SEM & Ln Mean \pm SEM & Range & \\
\hline Normal skin & 12 & $5.69 \pm 1.69$ & $1.06 \pm 0.41$ & $0.51 \rightarrow 20.0$ & - \\
\hline Healed wound & 9 & $7.73 \pm 2.54$ & $1.42 \pm 0.46$ & $0.29 \rightarrow 20.4$ & 0.55 \\
\hline Unhealed wound & 13 & $19.67 \pm 6.23$ & $2.60 \pm 0.24$ & $2.95 \rightarrow 89.7$ & 0.002 \\
\hline
\end{tabular}

9/13 cases matched biopsies of healed burn wound were obtained.

\section{IL-8 levels}

The amount of IL-8 produced by tissue biopsies from normal skin and healed and unhealed wounds is presented in Table 1 . There was a significant difference in IL-8 production among the 3 tissues assayed ( $p=$ 0.003 from ANOVA). The release of IL- 8 by healed and uninjured skin were similar, $5.7 \mathrm{ng} / \mathrm{ml}$ (range 0.1-20.1) vs. $7.7 \mathrm{ng} / \mathrm{ml}$ (range $0.2-20.4$ ) ( $p=0.55$ ). In contrast, the level of IL-8 produced by biopsies of unhealed wounds were significantly greater, $19.7 \mathrm{ng} / \mathrm{ml}$ (range 3.0-89.7) ( $p=0.002$ vs. uninjured). Subsequent experiments utilized the concentration ranges of IL-8 produced by these biopsies.

\section{Lattice contraction}

The inclusion of IL-8 inhibited FPCL contraction at 24 hours (Figure 1). The suppression had an optimal dose of $30 \mathrm{ng} / \mathrm{ml}$, at which FPCL contraction was $23 \%$ less

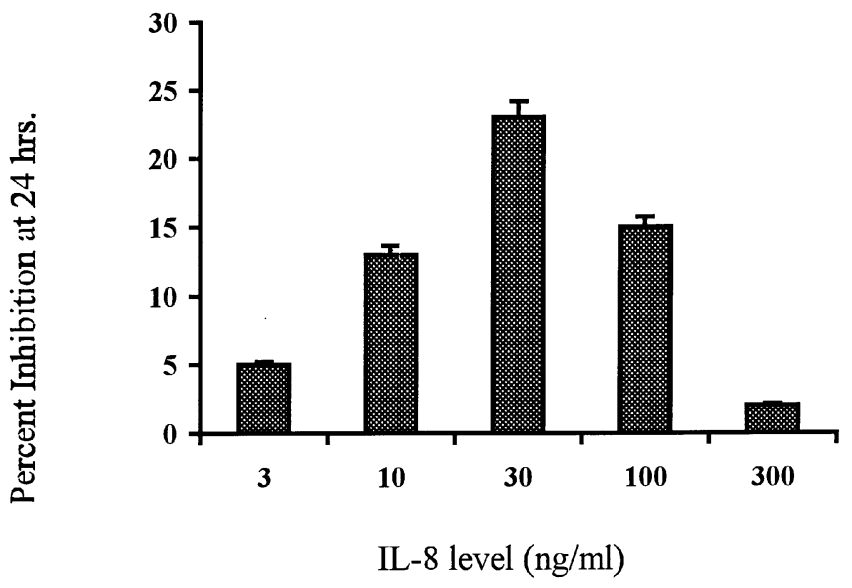

Figure 1. Dose response inhibitory effect of IL-8 on lattice contraction. FPCLs ( $n=12$ for each dose) were incubated with increasing doses of IL-8 and lattice contraction was measured at 24 hours. Error bars represent $\pm S D$. The percentage inhibition of lattice contraction compared to the control mean is shown. The maximum inhibition (23\%) was seen at an IL-8 concentration of $30 \mathrm{ng} / \mathrm{ml}$. All differences in inhibition were statistically significant from the control group using ANOVA with Dunnett's test. than PBS controls ( $n=12$ per group, $p=0.001$ ). IL-8 at $10 \mathrm{ng} / \mathrm{ml}$ or below and $100 \mathrm{ng} / \mathrm{ml}$ or above had no significant effect upon FPCL contraction. Although IL-8 inhibited the rate of FPCL during the initial 24 hours, it did not affect the rate of FPCL contraction after that initial 24-hour period. This finding implied that added IL-8 either has a short half-life or that it influenced fibroblasts during their initial encounter with polymerized collagen. The most inhibitory dose of IL-8 was in a narrow concentration range which was similar to the levels released by slowly healing wound biopsies.

One possible mechanism for FPCL contraction retardation is through the promotion of the arachidonic acid cascade and the release of prostaglandins. ${ }^{26}$ To investigate that possibility, indomethacin $(10 \mu \mathrm{g} / \mathrm{ml})$, a cyclooxygenase inhibitor, was added to lattices receiving IL-8 at $30 \mathrm{ng} / \mathrm{ml}$. As shown in Figure 2, indomethacin attenuated the effects of IL-8 and reinstated lattice contraction to control levels. Thus, indomethacin antagonized IL-8 retardation of FPCL contraction.

\section{Cell replication}

The effects of IL-8 on cell replication were measured using six strains of keratinocytes and two strains of fibroblasts. Cells were counted every other day until completely confluent, day 7-9 depending on the strain. The differences in cell count were only significant at these late time points; therefore, the concentration effects of IL-8 on cell number are reported for these days (the last measured day for all strains except one; the next-to-last measured day for that strain).

IL-8 concentration had no effect on fibroblast replication (data not presented). Increasing IL-8 concentration significantly decreased the replication of epidermal keratinocytes, $p<0.001$ (Figure 3). Compared to control (no IL-8 treatment), there was a modest, $12.5 \%$ (range 2-26), decrease at the $100 \mathrm{ng} / \mathrm{ml}$ concentration compared to control untreated cells. The decrease in final cell count was greater, $21 \%$ (range 7-31), when compared to the groups treated with $1-5 \mathrm{ng} / \mathrm{ml}$ IL- 8 , since these groups had the highest cell numbers. However, the increase in cell replication at low IL-8 concentrations was not significant $(p>0.2)$. Cell strains exhibited 


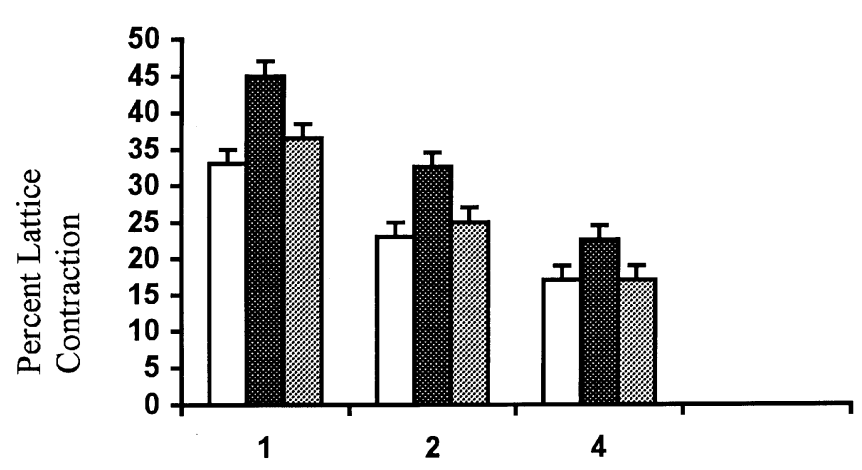

Time (days)

Figure 2. The inhibitory effect of IL-8 on lattice contraction is attenuated by indomethacin.FPCL ( $n=24$ for each bar) were incubated with PBS (white bars), IL-8 at $30 \mathrm{ng} / \mathrm{ml}$ (black stippling), or a combination of IL-8 $(30 \mathrm{ng} / \mathrm{ml})$ and indomethacin $(10 \mu \mathrm{g} /$ $\mathrm{ml}$ ) (gray stippling), and observed for 4 days. The graph depicts the average percentage contraction of the lattices over time. Error bars represent \pm SD. When compared to control, IL-8 at $30 \mathrm{ng} / \mathrm{ml}$ inhibited lattice contraction $23 \%$ at each time point measured ( $p=0.001$ ), using ANOVA with Dunnett's test, but the addition of the indomethacin reversed the inhibitory effect of the IL-8 to control levels of lattice contraction by 96 hours. Indomethacin alone had no significant effect on lattice contraction (data not shown).

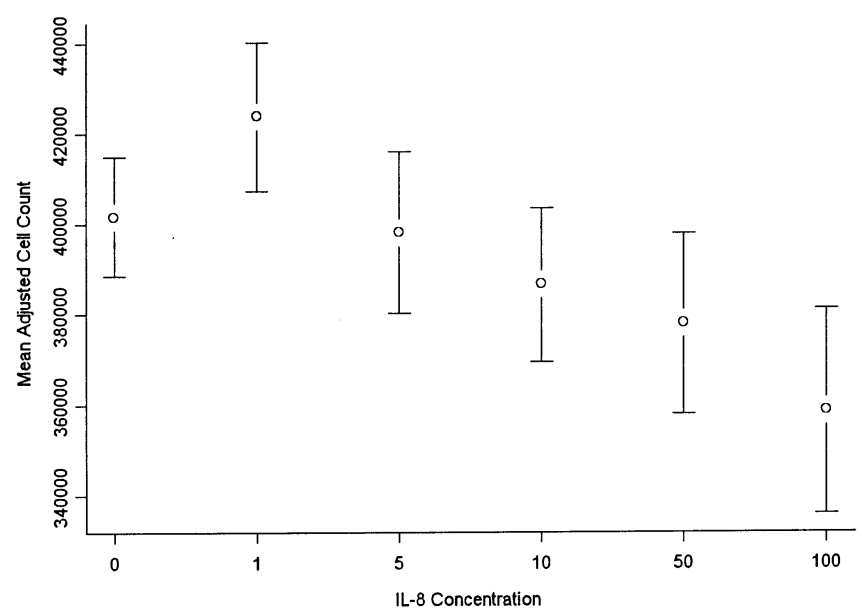

Figure 3. The effect of IL-8 on epidermal keratinocyte replication. Six strains of human keratinocytes were treated with the specified dose of IL-8 for 7-9 days. There is a significant inhibitory effect of IL-8 ( $p<0.001$, ANCOVA) on keratinocyte replication. The loess algorithm (see text) was used to model this relationship. The cell numbers at zero concentration differed significantly from the decreasing linear trend of cell numbers with concentration greater than one $(p=0.018)$. Values indicate mean \pm SE.

significant (4-fold) differences in replication rate, but the effect of IL-8 concentration was consistent across strains.
Table 2. ATP-induced fibroblast contraction

\begin{tabular}{lllc}
\hline & \multicolumn{2}{c}{ Cell length* $(\boldsymbol{\mu})$} & \\
\cline { 2 - 3 } Group & 0 minutes & $\mathbf{1 0}$ minutes & \% Cell contraction $\dagger$ \\
\hline Control & $24.48 \pm 5.0 \mathrm{U}$ & $3.75 \pm 1.1 \mathrm{U}$ & $85 \%$ \\
$\mathrm{IL}-8$ & $19.50 \pm 4.0 \mathrm{U}$ & $8.98 \pm 1.5 \mathrm{U}$ & $54 \% \ddagger$ \\
\hline
\end{tabular}

$n=84$ for all groups.

*Cell length measured 0 and 10 minutes after the addition of ATP.

$\dagger[1$ - (final length/initial length) $] \times 100$

$\doteqdot$ Difference $=31 \%, p=0.01$ vs. control

\section{Myosin ATPase activity}

Permeabilized cells in monolayer culture contract when ATP and its cofactors are added. The shortening of microfilaments through myosin ATPase activity induces cell contraction and can be used as an assay of myosin ATPase activity. Control fibroblasts contracted to $15 \%$ of their initial length 10 minutes after adding ATP, whereas IL-8 treated cells contracted to only $46 \%$ of their initial length ( $p=0.01$ ) (Table 2). Thus, IL-8 directly inhibited myosin ATPase. This result suggests a mechanism to explain how IL-8 retards FPCL contraction.

\section{Myosin light chain phosphorylation}

A potential mechanism linking retarded FPCL contraction and inhibited myosin ATPase activity is the phosphorylation state of MLC. Western Blot analysis of MLC, MLCK and $\beta$-actin are shown in Figure 4. Equal concentrations of lysate were loaded, indicated by the density of $\beta$-actin bands, an internal control for protein loading. The levels of the enzyme MLCK were equivalent between groups, indicating that IL-8 did not affect the levels of this protein kinase, responsible for MLC phosphorylation (Figure 4B). The levels of phosphorylated and nonphosphorated MLCs by immunoblotting showed differences between treatment groups. The isoforms of MLC appears in three bands, each designating a different phosphorylation state of the MLC. ${ }^{27}$ The top band, the essential MLC band, is an unphosphorylated form that is constitutively expressed; the middle band, is regulatory MLC, in its unphosphorylated form; the lowest band is regulatory MLC in its phosphorylated form. The higher the proportion of phosphorylated regulatory MLC the greater the myosin ATPase activity. The level of the phosphorylated regulatory MLC was negligible in the IL-8 alone treatment group. The control and the indomethacin IL-8 combination treatment groups showed equivalent levels of phosphorylated regulatory MLC (Figure 4C). Therefore, IL8 inhibited the phosphorylation of the regulatory MLC independent of MLCK protein levels.

\section{Cellular morphology}

The induction of morphological changes in fibroblasts residing in a collagen lattice by IL-8 was seen by phase 

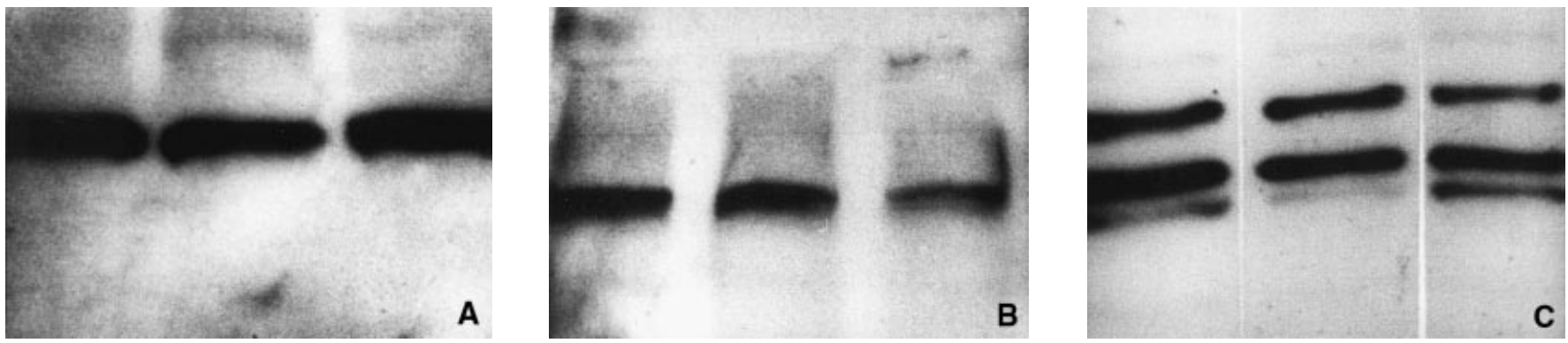

Figure 4. Western blot analysis of MLCK and MLC in fibroblast cultures. Representative blots of the effect of IL-8 with and without indomethacin on the expression of MLCK and MLC in fibroblasts in culture are shown. In each lane, $20 \mu \mathrm{g}$ of protein was loaded. In each blot, lane 1 is control, lane 2 is $\mathrm{LL}-8(30 \mathrm{ng} / \mathrm{ml})$ and lane 3 is the combination of $\mathrm{IL}-8$ and indomethacin ( $10 \mu \mathrm{g} / \mathrm{ml})$. As shown in (A), blotting with $\beta$-actin confirmed equal loading of the gel. (B) The expression of MLCK among the three treatment groups is also equal. (C) IL-8, alone, is shown to have a profound effect upon the phosphorylation of MLCs and this effect is blocked with indomethacin.

contrast and fluorescent microscopy (Figure 5). By phase contrast dermal fibroblasts in collagen were elongated with a bipolar morphology (Figure 5A). In the presence of IL-8, fibroblasts were less elongated and had a dendritic like appearance with multiple extensions (Figure 5B). As seen in Figure 6A, microfilaments in untreated cells were organized as fine filaments. Cells within FPCL treated with IL-8 (Figure 6B) showed few microfilaments and the actin appeared as fluorescent aggregates. IL-8 hindered the organization of filamentous-actin into cytoplasmic microfilaments. This is in agreement with the actions of elevated prostaglandins. ${ }^{27}$

\section{DISCUSSION}

Normal wound healing is an orchestrated activity which proceeds from initial inflammation through cell replica- tion and matrix synthesis to remodeling. It is not surprising that disruption of this progression would cause deficiencies in healing. Clinically, wounds that display inadequate inflammation, e.g., during steroid treatment or malnutrition, or excessive inflammation, e.g., during infection or autoimmune disease, heal poorly. Simplistically, these clinical observations have led to the hypothesis that abnormal inflammation results in abnormal healing. This article attempts to examine this possibility more specifically. Excessive inflammation was quantitated by determining the concentration of a chemokine generally thought to have little effect on noninflammatory cells. The effects of chemokine treatment on woundassociated cells provides a mechanistic rational for inflammatory effects on delayed wound healing. Elevating and/or prolonging the presence of IL-8 over an extended period of time appears to impair the repair process. We
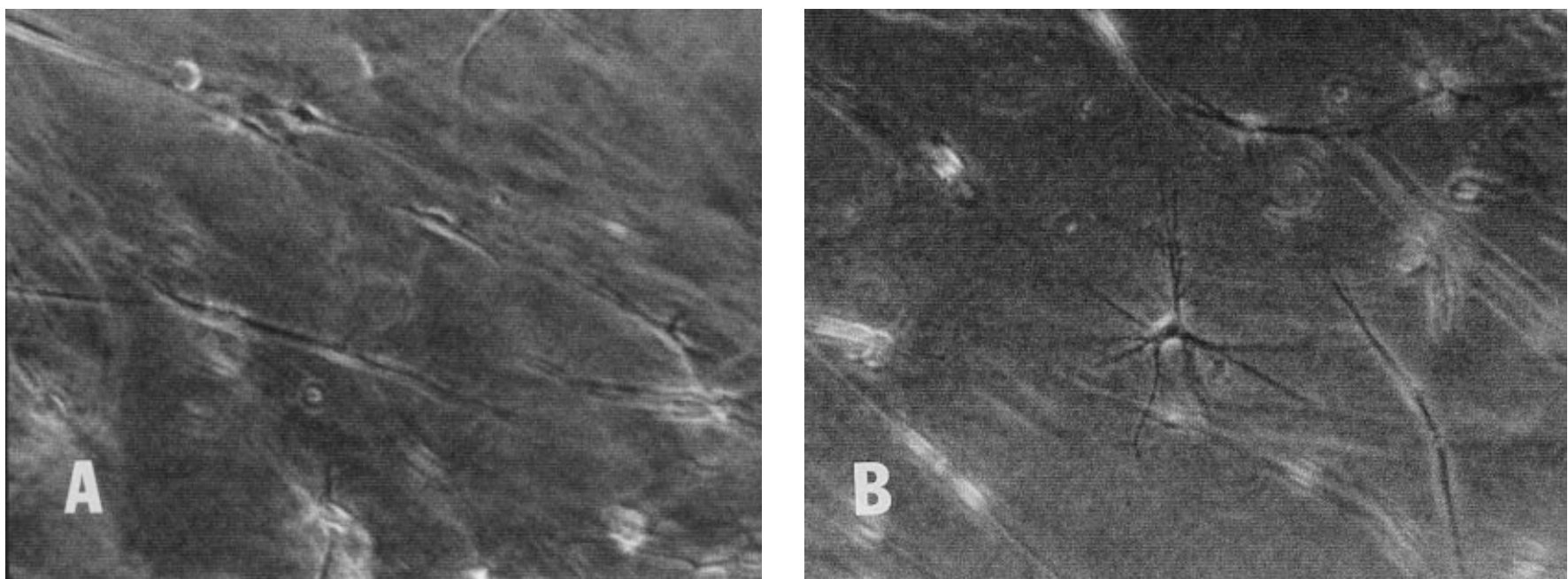

Figure 5. Effect of IL-8 on cellular morphology shown using phase contrast microscopy of cells within a FPCL. (A) Control lattice showing cells with an elongated bipolar morphology typical of fibroblasts within a collagen lattice. (B) Typical fibroblast within a collagen lattice that has been treated with IL-8 showing multiple short actin extensions and a stellate appearance. (Original magnification $\times 20$ ). 


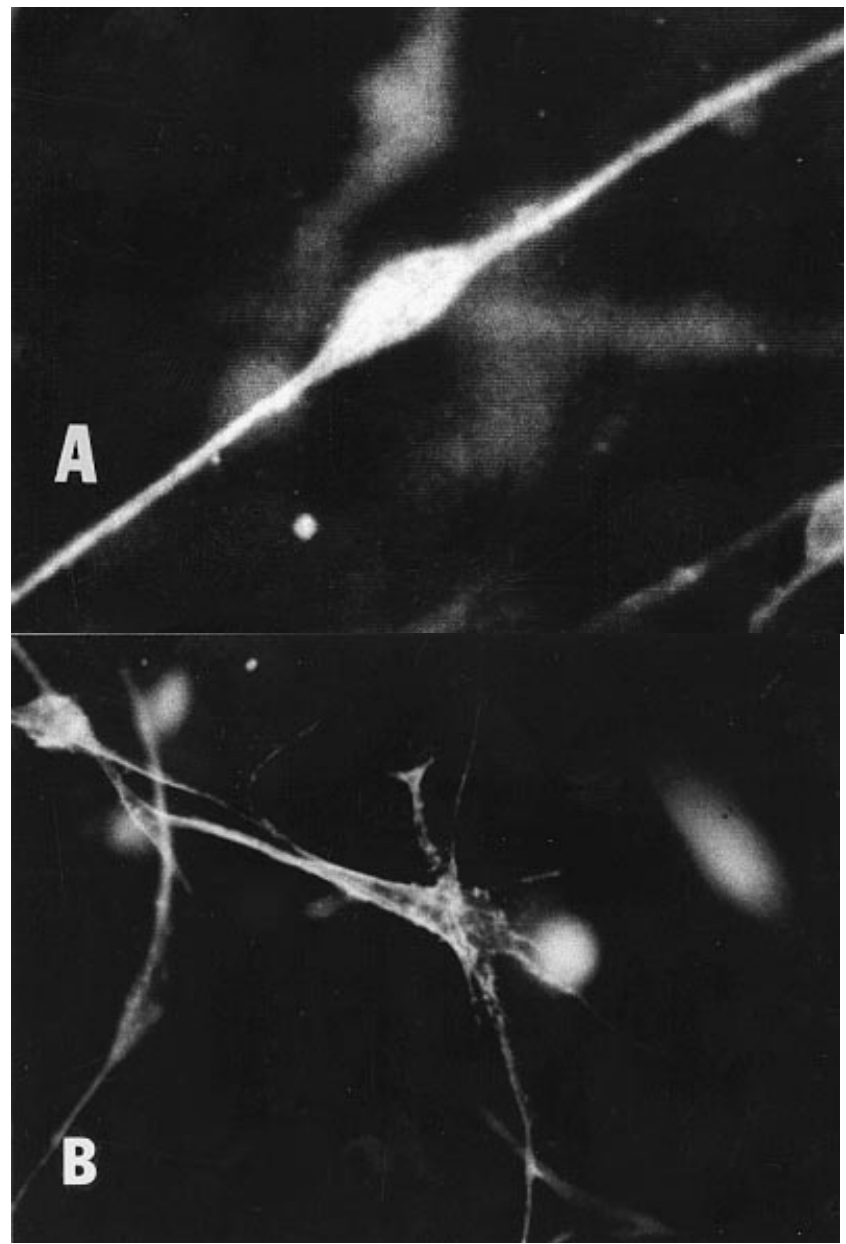

Figure 6. Effect of IL-8 on cellular morphology using fluorescent phalloidin staining of cells within a FPCL. Rhodamine phalloidin was used to depict filamentous actin within the fibroblasts. (A) Control cells exhibit fine actin filaments throughout their cytoplasm, whereas in (B), IL-8 treated cells show actin that has aggregated in clumps and has lost its fine filamentous appearance.

propose that an increase in IL-8 levels within burned skin results in slowly healing wounds.

Delayed wound healing does not mean that these wounds are chronic. Most clinicians have cared for patients who have wounds that heal more slowly than expected. In many cases the delay is related to infection, malnutrition, or pre-existing disease. In some cases these factors are not present but wound healing progresses slowly or poorly. Our findings suggest that healing may be impaired but not prevented by changes in the delicate balance between numerous cell types and the quantity of released products. Too much or too little of certain products may upset that balance. The present study focusses on analyzing biopsies of a particular type of wound (burn) in apparently healthy patients that sometimes did not heal within the usual time. Normally, such wounds would be expected to close by contraction and epithelialization within several weeks. Here, prolonged or elevated levels of IL- 8 appear to impair the repair process. In vitro studies show elevated IL-8 concentrations negatively affected both the morphology and functions of fibroblasts and keratinocytes. This suggests that the prolonged or elevated IL-8 levels alter cell morphology and function. Because full-thickness human wound closure involves epithelialization and wound contraction, ${ }^{27}$ these are the specific cells that achieve wound closure by re-epithelialization and contraction; dysfunction of these cells will likely impair wound closure. While there are probably numerous reasons for wounds not to heal rapidly, we hypothesize that excess inflammation is an important one in this group of burn wounds.

Although these data show that a particular chemokine, IL-8, is present in increased concentrations in delayed healing burn wounds, the cause for increased concentrations of this cytokine is not known. Infected wounds do not heal, but these wound were documented by quantitative biopsy to not be infected. Nevertheless, bacteria were likely present as colonizers of the wound surface. Because the wounds lack a cornified epidermal barrier, these low numbers of bacteria and their byproducts would interact with immunocompetent cells within the wound. Endotoxin is a potent direct and indirect stimulator of IL-8 release. ${ }^{21}$ Staphylococcal enterotoxin A increases IL-8 synthesis in fibroblast-like synovium cells. ${ }^{23}$ Alternately, tissue damage early after burn injury also induces IL-8 production in the absence of infection. ${ }^{5}$ The presence of a chemoattractant for neutrophils, macrophages and lymphocytes ${ }^{4}$ such as IL-8, is likely since these wounds are well populated by these cell types. Non-healing wounds exhibit greater densities of inflammatory cells that remain until wound closure occurs. The levels of inflammatory cytokines and chemokines are initially elevated in open wounds but decline as healing advances. ${ }^{20}$ The present and our previous work ${ }^{5}$ document elevated levels of IL-8 during the inflammatory phase of repair that appear to decline to normal levels when the wound is healed. Taken together, this information suggests that some inflammation is expected during normal wound healing and that concomitant trauma or infection likely increases the amount of inflammation and its mediators that are present.

Wound contraction requires that fibroblasts organize and compact collagen fibers into thicker fiber bundles. The contraction of FPCL similarly depends upon fibroblast organization of collagen. ${ }^{19}$ Morphological changes in cells induced by IL-8 include minimizing the prominence of focal adhesion and microfilaments that are not incorporated into stress fibers. ${ }^{28}$ These changes would 
be expected to significantly alter the ability of cells to interact with the surrounding matrix.

FPCL contraction is regulated by a variety of agents including prostanoids. The IL-8 induced morphological changes in human fibroblasts suspended in collagen are similar to those reported for $\mathrm{PGE}_{2}{ }^{26}$ By Rh-Phalloidin staining of F-actin microfilaments, IL-8 disrupts microfilaments in a manner consistent with that reported for IL-8 treated endothelial cells. ${ }^{29}$ Impairment of myosin ATPase may be responsible for the inhibition of FPCL contraction by IL-8 exposure. Myosin is both a structural protein and an ATPase enzyme. Myosin has two pairs of associated MLCs in which the phosphorylation of the regulatory pair maximizes ATPase activity. Phosphorylation of the regulatory MLCs is catalyzed by the kinase enzyme MLCK. It is proposed that IL-8 reduces myosinATPase activity by blocking the phosphorylation of the regulatory MLCs by MLCK. In vivo, the inhibition of fibroblast myosin ATPase may reduce fibroblast migration into the wound site as well as reduce the organization of collagen fiber bundles. ${ }^{24}$ These studies point to the phosphorylation of the regulatory MLCs as a possible mechanism for the effects of IL-8 directly on fibroblasts. Inhibition of these two activities will directly contribute to retarded wound closure.

The increased concentration of a single cytokine is not likely to be sole reason for the impaired healing observed in this group of slowly healing burn wounds. Poorly healing and chronic wounds are a heterogenic group and are likely to result from a diverse group of causes. Abnormal concentrations of other cytokines, growth factors or mediators may contribute to disordered healing or, alternatively, compensate for the inhibition. For example, IL-1 also inhibits FPCL contraction by fibroblasts. ${ }^{30}$ The effect of IL-8 on fibroblasts that impair wound closure may be reversed by another growth factor secreted later in the wound healing cascade. Transforming growth factor- $\beta$ is present in healing wounds and accelerates FPCL contraction. ${ }^{31}$ The observed restoration of FPCL contraction in the latter days of culture and the delayed but eventual contraction of wounds in patients may be due to the presence of this factor or simply result from the turnover of IL-8 in FPCL model and human tissues. Finally, the actual concentration of IL-8 in any specific wound is the consequence of ongoing synthesis and degradation. It will be necessary to quantitate IL-8 production in serial biopsies of normal and abnormally healing tissue to better understand how changes in the concentration of this chemokine effects wound healing.

Every model has limitations. This one uses the chemokine concentration released by a tissue biopsy as a reflection of the chemokine concentration in the tissues of a wound. Although there are problems with this assumption, we do not believe that a better model exists. Mediators are released by cells into tissues, where they can act in an autocrine or paracrine fashion. The IL-8 released into the medium by tissue biopsies is likely a similar process. Secondly, the absolute concentration of IL-8 determined in this model may not exactly reflect the in vivo situation since there was only a 6 -mm biopsy in 3 $\mathrm{ml}$ of medium. However, the range of IL-8 concentrations found in the slowly healing wounds correlated with the concentrations of IL-8 which decreased cellular activities associated with wound healing, a fact that support the validity of the model. Quantitating the amount of cytokine in a biopsy may not indicate the amount of cytokine that is functionally active. Many mediators are stored in the skin but are not active until released or activated. Biopsies of different types may have different numbers of cells, cells of different lineages or vary in other ways as a cause for the differences in cytokine production. Determining these differences will require a future study to document the mechanisms for increased IL-8 production in unhealed wounds. Nevertheless, whatever the cause, unhealed burn wounds are producing higher levels of IL-8 per unit area and the cells in the tissue are exposed to these increased concentrations of cytokines. Finally, although the process of removing the tissue and placing it into medium will likely activate some cells and cytokine, the relative effects from each tissue show clear differences.

In normal wound healing, an inflammatory response is followed by the proliferative phase of repair with wound contraction and re-epithelialization, resulting in wound closure. Our experimental data, coupled with clinical observations suggest that overproduction of IL-8 in a wound associated with increased or prolonged inflammation may overwhelm the normal wound healing system and impair closure. Furthermore, wound infection, and resulting increased inflammation, would be detrimental to the ability of the host to progress to successful healing. This hypothesis provides an additional rationale for the well-documented failure of infected wound to heal. The removal of the inflammatory source would eliminate the stimulus for the production of IL- 8 and other inflammatory cytokines, thereby allowing resumption of the normal wound closure. Preventing the invasion or promoting the exodus of inflammatory cells would be expected to reduce the concentrations of IL-8. This means that ongoing inflammation within nonhealing wounds and the known increased synthesis and release of IL-8 from these wounds would contribute to retarded wound closure. 


\section{ACKNOWLEDGMENTS}

This study was supported by grants GM 50967 (W. Garner), GM 41343 (H.P. Ehrlich), GM 50401 (D. Remick), and F32 GM17566 (J. Iocono) from the National Institutes of Health.

\section{REFERENCES}

1. Harada A, Seiko N, Akahoshi T, Mukaida N, Matsushima K. Essential involvement of interleukin-8 (IL-8) in acute inflammation. J Leuk Biol 1994;56:559-64

2. Schroder JM. Cytokine networks in the skin. J Invest Derm 1995; 105(1 Suppl.):20S-24S.

3. Hunt TK, Ehrlich HP, Garcia JA, Dunphy JE. Effects of vitamin A on reversing the inhibitory effect of cortisone on healing open wounds in animals and man. Ann Surg 1969;170:663-41.

4. Zucehlen $\mathrm{R}$, Walz $\mathrm{A}$, Rot $\mathrm{A}$. In vitro and in vivo activity of pathophysiology of human IL8 and retarded peptides. Int Rev Exp Path 1993;34B:27-42.

5. Garner WL, Rodriguez JL, Miller CG, Till GO, Rees RS, Smith DJ, Remick DG. Acute skin injury releases neutrophil chemoattractants. Surgery 1994;116:42-8.

6. Konstantinova NV, Duong DM, Remenyik E, Hazarika P, Chuang A, Duvic M. Interleukin- 8 is induced in skin equivalents and is highest in those derived from psoriatic fibroblasts. J Invest Derm 1996;107:615-21.

7. Yoshimura T, Matushima K, Tanaka S, Robinson EA, Appella E, Oppenheim JJ, Leonard, EJ. Purification of a human monocytederived neutrophil chemotactic factor that has peptide sequence similarity to other host defense cytokines. Proc Natl Acad Sci USA 1987;84:9233-7.

8. Clore GM, Gronenborn AM. NMR and X-ray analysis of the threedimensional structure of interleukin-8. Cytokine 1992;4:18-40.

9. Modi WS, Dean M, Seuanez HN, Mukaida N, Matsushima K, O'Brien SJ. Monocyte-derived neutrophil chemotactic factor (MDNCF/ IL8) resides in a gene cluster along with several other members of the platelet factor 4 gene superfamily. Hum Genet 1990;84: 185-7.

10. Mukaida N, Shiroo M, Matsushima K. Genomic structure of the human monocyte-derived neutrophil chemotactic factor IL-8. J Immunol 1989;143:1366-71.

11. Holmes WE, Lee J, Kuang WJ, Rice GC, Wood WI. Structure and functional expression of a human interleukin- 8 receptor. Science 1991;253:1278-80.

12. Oppenheim JJ, Zacharive COC, Mukaida N, Matsushimer K. Preparation of proinflammatory supergene intercrine cytokine family. Ann Rev Immunol 1991;9:617-48.

13. Kusner DJ, Luebbers EL, Nowinski RJ, Konieczkowski M, King $\mathrm{CH}$, Sedor J. Cytokine- and LPS-induced synthesis of interleukin8 from human mesangial cells. Kidney Int 1991;39:1240-08.
14. Baggiolini M. Chemotactic and inflammatory cytokines - CXC and CC proteins. In: Lindley IJD, Westwick J, Kunkel S, editors. The chemokines. New York: Plenum Press, 1993:1-11.

15. Leung T, Chen XQ, Manser E, Lim L. The p160 RhoA-binding kinase ROK alpha is a member of a kinase family and is involved in the reorganization of the cytoskeleton. Mol Cell Biol 1996;16: 5313-27.

16. Yam Y, Saito Y, Narumiya S, Sump BE. Involvement of Rho p21 in cyclic strain-induced tyrosine phosphorylation of focal adhesion kinase (pp125 FAK), morphological changes and migration of endothelial cells. Biochem Biophys Res Comm 1996;224:508-15.

17. Kunkel SL, Lukacs N, Strieter RM. Chemokines and their role in human disease. Agents Actions 1995;46:11-22.

18. Bell EB, Ivarsson, Merrill C. Production of a tissue-like structure by contraction of collagen lattices by human fibroblasts of different proliferative potential in vitro. Proc Natl Acad Sci USA 1979; 76:1273-8

19. Ehrlich HP. Wound closure: Evidence of cooperation between fibroblasts and collagen matrix. Eye 1988;2:149-57.

20. Ehrlich HP, Rajaratnam JBM. Cell locomotion force versus cell contraction forces for collagen lattice contraction: an in vitro model of wound contraction. Tissue Cell 1990;22:407-17.

21. DeForge LE, Remick DG. Sandwich ELISA for detection of picogram quantities of interleukin-8. Immunol Invest 1991;20:89-97.

22. Garner WL, Smith DJ, Jr, Zuccaro C, Marcelo CL, Rodriguez JL. The effects if burn blister fluid on keratinocyte replication and differentiation. J Burn Care Rehab 1993;14:127-31.

23. Ehrlich HP. The modulation of contraction of fibroblast populated collagen lattices by types I, II, and III collagen. Tissue Cell 1988; 20:47-50.

24. Ehrlich HP, Griswold TR, Rajaratnam JBM. ATP-induced cell contraction with epidermolysis bullosa dystrophica recessive and normal dermal fibroblasts. J Invest Derm 1986;86:96-100.

25. Hastie TJ, Tibshirani RJ. Generalized additive models. New York Chapman and Hall, 1990.

26. Ehrlich HP, White ME. Effect of increased concentrations of prostaglandin E levels with epidermolysis bullosa dystrophica recessive fibroblasts within a populated collagen lattice. J Invest Derm 1983;81:572-5.

27. Kolodney MS, Elson EL. Correlation of myosin light chain phosphorylation with isometric contraction of fibroblasts. J Biol Chem 1993;268:23850-5.

28. Dunlevy JR, Couchman JR. Interleukin-8 induces motile behavior and loss of focal adhesions in primary fibroblasts. J Cell Sci 1995; 108:311-21.

29. Verin AD, Patterson CE, Day MA, Garcia JG. Regulation of endothelial cell gap formation and barrier function by myosin-associated phosphatase activities. Am J Physiol 1995;269:L99-108.

30. Ehrlich HP, Wyler DJ. Fibroblast contraction of collagen lattices in vitro: inhibition by chronic inflammatory cell mediators. J Cell Physiol 1983;116:345-51.

31. Monesano B, Orci L. Transforming growth factor $\beta$ stimulates collagen-matrix contraction by fibroblasts. Proc Nat Acad Sci USA 1988;85:4894-7. 